\title{
Beta-adrenoceptor-blocking drugs, growth hormone and acromegaly
}

\author{
JOHN FEELY \\ M.B., B.Sc., M.R.C.P.I. \\ Department of Pharmacology and Therapeutics, University of Dundee, \\ Ninewells Hospital, and Medical School, Dundee DD1 9SY
}

\begin{abstract}
Summary
Chronic treatment with oxprenolol or propranolol in active hypertensive patients was associated with elevation of serum growth hormone (GH). Propranolol, $80 \mathrm{mg}$ orally, caused a marked rise in GH in 3 of 4 acromegalic patients.
\end{abstract}

\section{Introduction}

Beta-adrenoceptor-blocking agents are extensively used in the management of hypertension and ischaemic heart disease. These agents may also be used in acromegalic patients where hypertension and ischaemic heart disease occur commonly (Martins et al., 1977). There is, however, some evidence that propranolol, alone in normal subjects (Imura et al., 1971; Maclaren, Taylor and Raiti, 1975), and combined with glucagon in acromegalic subjects (Coutant, Vandeweghe and Vermeulen, 1977), may increase growth hormone (GH) concentrations. The object of this study was to determine if chronic treatment with oxprenolol or propranolol in hypertensive patients is associated with elevation of $\mathrm{GH}$, and to determine the influence of propranolol alone on GH levels in acromegalic patients.

\section{Materials and methods}

Fifteen ambulatory hypertensive out-patients (aged 25-65 years) receiving chronic treatment with oxprenolol (5 patients) or propranolol and concomitant diuretic therapy in 11 patients were matched for age, sex, blood pressure control and disease state, with 15 patients receiving antihypertensive therapy other than $\beta$-blockers, clonidine or $\alpha$-methyldopa (i.e. diuretics, vasodilators, or peripheral adrenergic neurone blocking agents). Growth hormone levels were measured by radioimmunoassay, on samples taken in the afternoon immediately following assessment at a busy clinic. Four supine patients ( 3 male, 1 female) with active acromegaly were given propranolol $80 \mathrm{mg}$ orally, after an overnight fast, one week following a glucose tolerance test (GTT) and had serial samples taken over 3 hours via an indwelling cannula for estimation of $\mathrm{GH}$ and plasma propranolol (by a gas-liquid chromatographic method). Statistical analysis was by a Wilcoxon non-parametric test and correlation by method of least squares regression.

\section{Results}

In the hypertensive group GH levels were higher $(P<0.05)$ in oxprenolol/propranolol patients $(5 \cdot 8 \pm 2 \cdot 1 \mathrm{mu}$. 1 , mean \pm s.e.mean) than in the control patients $(0.9 \pm 0.3 \mathrm{mu} . / \mathrm{l})$ although plasma glucose levels were similar, $5.5 \pm 0.4$ and $5.1 \pm 0.2 \mathrm{mmol} / \mathrm{l}$ respectively.

In acromegalic patients, glucose did not suppress the elevated GH levels. The plasma glucose did not change significantly throughout the propranolol tesd and in all patients, except one, D, there was a marke rise in $\mathrm{GH}$ following propranolol (Fig. 1). This latter patient in addition did not show any GH response to insulin induced hypoglycaemia. There was a positive correlation $(r=0.63, \quad P<0.05)$ between the logarithms of the percentage increase

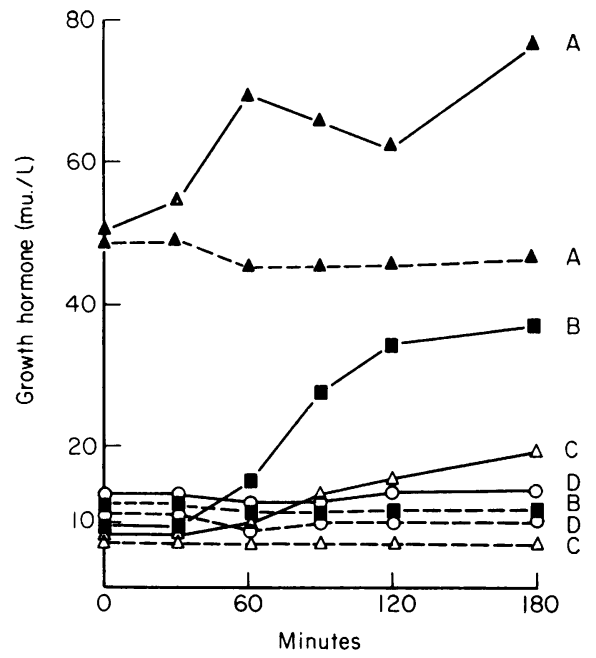

Fig. 1. Growth hormone levels in 4 acromegalic patients following glucose $(---)$, and following propranolol $(\longrightarrow) 80 \mathrm{mg}$ orally. 
in $\mathrm{GH}$ levels (in the 3 responders) and of plasma propranolol concentration.

\section{Discussion}

In addition to dopaminergic control, the adrenergic system is an important regulator of growth hormone secretion. Alpha blockade and $\beta$ stimulation suppress GH secretion, while $\beta$-blockade augments GH secretion in both normal and acromegalic subjects (Cryer and Daughaday, 1977). Chronic elevation of GH may be cardiotoxic in acromegaly (Martins et al., 1977) although its possible effects on an ischaemic or hypertensive heart is unknown. Acute treatment with propranolol has been shown by Imura et al. (1971), and Maclaren et al. (1975), to increase GH levels, however GH did not increase in a study by Lee, Thompson and Blizzard (1974). In this study in active hypertensive patients, chronic treatment with non-selective centrally acting $\beta$ blockers was associated with elevation of $\mathrm{GH}$, while a normal GH response to glucose loading has recently been noted by Day et al. (1979) in recumbent fasting hypertensive patients receiving chronic propranolol or atenolol therapy. Propranolol may increase the $\mathrm{GH}$ response to many stimuli including moderate exercise (Maclaren et al., 1975); however, more detailed studies are necessary to determine whether GH remains elevated for a greater part of the day in patients receiving $\beta$-blockers. It has been suggested by Sherman et al. (1978) that oral contraceptives may induce growth and hormonal secretion in otherwise silent pituitary microadenomata, which occur in $5-10 \%$ of the population, and it is also possible that term treatment with $\beta$-blockers may facilitate the development of pituitary adenomata and acromegaly.

The variability in the response of some acromegalic patients to hypoglycaemia, propranololglucagon, thyrotrophin-releasing hormone and Ldopa has over the last decade led to the suggestion (Cryer and Daughaday, 1969; Goldfine, 1978) that some degree of hypothalamic control of $\mathrm{GH}$ persists in many acromegalic patients and autonomous pituitary secretion develops in the remainder. It is possible that patient $D$ who did not respond to either insulin/hypoglycaemia or propranolol is in the latter category. The significant positive relationship between plasma propranolol concentration and $\mathrm{GH}$ response in the other acromegalic patients further supports the role of the sympathetic system in GH secretion. This marked elevation of $\mathrm{GH}$ following propranolol, may be an important consideration when assessing $\mathrm{GH}$ levels, and initiating therapy with $\beta$-blockers in acromegalic patients.

\section{Acknowledgments}

I am grateful to the staff of the Hypertension and Endocrine Clinics and the Endocrine Division of Biochemical Medicine, Ninewells Hospital, Dundee, for their co-operation in this study.

\section{References}

Coutant, G., Vandeweghe, M. \& Vermeulen, A. (1977) Comparison of TRF, propranololglucagon, insulin and glucose stimulation tests in acromegaly. Hormone and Metabolic Research, 9, 17.

CRYer, P.E. \& Daughaday, W.H. (1969) Regulation of growth hormone secretion in acromegaly. Journal of Clinical Endocrinology and Metabolism, 29, 386.

Cryer, P.E. \& Daughaday, W.H. (1977) Adrenergic modulation of growth hormone secretion in acromegaly. Journal of Clinical Endocrinology and Metabolism, 44, 977.

Day, J.L., Simpson, N., Metcalfe, J. \& Page, R.L. (1979) Metabolic consequences of atenolol and propranolol in treatment of essential hypertension. British Medical Journal, 1, 77.

GoldFINE, I.D. (1978) Medical treatment of acromegaly. Annual Review of Medicine, 29, 407.

ImURA, H., Kato, Y., IKeda, M., MoRimoto, M. \& Yawata, M. (1971) Effect of adrenergic-blocking drugs or stimulating agents on plasma growth hormone, immunoreactive insulin and blood free fatty acid levels in man. Journal of Clinical Investigation, 50, 1069.

Lee, P.A., Thompson, R.G. \& Blizzard, R.M. (1974) Relationship of the adrenergic nervous system and growth hormone release in normal adults and children with various growth disorders. Metabolism, 23, 595.

Maclaren, N.K., Taylor, G.E. \& Raiti, S. (1975) Propranolol augmented, exercise induced human growth hormone release. Pediatrics, 56, 804.

Martins, J.B., Kerber, R.E., Sherman, B.M., Marcus, M.L. \& ERHARDT, J.C. (1977) Cardiac size and function in acromegaly. Circulation, 56, 863.

Sherman, B.M., Schlechte, J., Halmi, N.S., Chapter, F.K., Harris, C.E., Duello. T.M., VanGilder, J. \& GranNer, D.K. (1978) Pathogenesis of prolactin-secreting pituitary adenomas. Lancet, ii, 1019. 